\title{
Age and complementarity in scientific collaboration
}

\author{
Matthias Krapf
}

Received: 14 October 2013 / Accepted: 24 September 2014 / Published online: 30 October 2014

(C) Springer-Verlag Berlin Heidelberg 2014

\begin{abstract}
I model research quality as the outcome of a CES production technology that uses human capital measured by publication records as inputs. Investigating a sample of scientific publications with two co-authors, I show that the CES-complementarity parameter is a function of the age difference of the authors. Complementarity is maximized if the age difference between the authors is about 10 years. Two theories are presented which may explain this finding. According to these models, older and younger researchers differ not only in their skill levels but also in the types of their skills and their interpersonal relationships.
\end{abstract}

Keywords Academic collaboration - CES technology · Team production · Human capital

\section{Introduction}

Not all intellectual collaboration is created equal. A vast existing literature on coauthorship has compared single-authored articles with co-authored articles, and articles with fewer authors with articles with more authors. In this paper, in contrast, I use a sample of articles written by two people, thus keeping the number of authors per article constant. The idea is that when two people work together, the quality of what they produce depends not only on person A and person B, but also on the quality of their relationship. The relationship represents a third entity, which matters in the production process. My analysis shows that the age composition of collaborating authors is highly correlated with their relationship. A measure of the relationship's quality is

\footnotetext{
M. Krapf $(\varangle)$

Département d'économetrie et d'économie politique (DEEP), Faculté des Hautes Etudes Commerciales (HEC), Université de Lausanne, 1015 Lausanne, Switzerland e-mail: matthias.krapf@unil.ch
} 
Table 1 Article quality measured by CLm

\begin{tabular}{llll}
\hline & $(1)$ & $(2)$ & $(3)$ \\
\hline Constant & $16.323 * * *$ & $-142.222 * * *$ & $-103.448 * * *$ \\
& $(0.316)$ & $(36.912)$ & $(37.113)$ \\
Number of authors & $2.039 * * *$ & $1.885 * * *$ & $4.907 * * *$ \\
& $(0.166)$ & $(0.169)$ & $(0.446)$ \\
Co-authors squared & & & $-0.534 * * *$ \\
& & & $(0.080)$ \\
Year & & $0.079 * * *$ & $0.058 * * *$ \\
& & $(0.019)$ & $(0.019)$ \\
R ${ }^{2}$ & 0.0087 & 0.0097 & 0.0149 \\
Observations & 19,606 & 19,606 & 19,606 \\
\hline
\end{tabular}

maximized if one author is 10 years older than the other. The average age difference in my sample of roughly 9 years is very close to this optimum, which suggests a selection problem. I explore different explanations for the observed phenomenon, but one should keep in mind that factors that are not accounted for in this study may drive both, age composition and productivity.

A number of studies have dealt with co-authored articles. Laband and Tollison (2000) report a steady increase in both, incidence of co-authorship, i.e., the fraction of co-authored papers, as well as in the number of authors per co-authored paper over the last decade. Research by Wuchty et al. (2007) shows that teams have become increasingly important in all scientific disciplines. There is evidence that this trend toward more co-authorship was beneficial. ${ }^{1}$ But, team work is also associated with coordination costs. Starting with Alchian and Demsetz (1972), economists have become interested in designing incentive structures to render team work more efficient. Prat (2002) investigates the optimal composition of teams given the degree of complementarity of the team members' tasks. He finds that the more complementary the inputs of its members, the more homogeneous a team should be.

This paper uses publication data for all current faculty members of departments of economics and business administration at German, Austrian and Swiss universities. Table 1 documents that the findings discussed above also hold for the data and output measure used in this paper: article quality as measured by the Combes and Linnemer (2010) journal-quality weighting scheme CLm is closely related to the number of authors in my sample. CLm assigns positive weights to all journals listed by EconLit with a maximum of 100 attained by the Quarterly Journal of Economics. The number of co-authors has a significant positive effect on output across all specifications. Specification (2) confirms that the effect is lower if a linear time trend is included because both, co-authorship and German economists' tendency to publish in international journals, have increased over time. In specification (3), I introduce a squared

\footnotetext{
1 Co-authorship reduces publication uncertainty through diversification (Barnett et al. 1988) and leads to a higher quality of articles as measured by acceptance rates or citations (Laband 1987; Ursprung and Zimmer 2007).
} 
term for the number of authors. Quality is highest when an article has 4.6 authors. But, as suggested by the very low R-squared, productivity depends on many other factors that I did not control for and that may also be correlated with the number of authors.

It is intuitive that co-authored articles are of higher quality. When scholars work together, each of them can specialize in the task that corresponds to his or her comparative or even absolute advantage. But why, exactly, is some collaboration between two researchers more productive than others? One explanation comes from an emerging literature in psychology, which emphasizes the importance of the social environment and relationships for human creativity. ${ }^{2}$ Wuchty et al. (2007) describe how the focus in the history and sociology of science has moved from the individual genius to teams. De Solla Price and Beaver (1966) regard the global research community as forming a network referred to as the 'invisible college,' in which geographic boundaries and proximity have become less important. This literature regards a team as more than the sum of its members. The relationship between collaborating individuals represents a third entity, which determines their joint productivity.

The objective of this paper is to examine this third entity. It shows that age is correlated with the extent of complementarity of the team members' inputs. I use variation in quality in a set of articles with exactly two co-authors rather than variation in number of authors. The employed method is a newly developed two-step technique. The structure of the paper is as follows. Section 2 outlines the first step, in which a CES production function serves to measure complementarity in a specific collaboration when article output and human capital of the two authors are given. This strategy allows me to measure the quality of the pairs controlling for individual abilities. Section 3 describes the data. In the second step, the revealed, team-specific complementarity parameter is regressed on the average age of the authors and on their age difference. The results are presented in Sect. 4.2. The main finding is that pairs of co-authors are most productive when the age difference between the authors is about 10 years. In Sect. 5, I develop theoretical explanations of the complementarity parameter. Section 6 presents survey-based tests of these theories. Section 7 concludes.

\section{Variation in complementarity}

Scientific collaboration is teamwork. Therefore, it might seem straightforward to think that research output is the outcome of a corresponding teamwork production function. Productivity therefore might be harmed by shirking (see Alchian and Demsetz 1972). Collaborating scientists, however, can usually observe each other's inputs pretty well and have the opportunity to retaliate, if necessary. Hence, their collaboration is not likely to represent a non-cooperative Nash equilibrium. In the framework, I will present each individual has a given amount of human capital, which is measured by past or average yearly output, and which is always fully employed.

My unit of analysis is published articles that have exactly two authors. Assume that the quality $Y_{i}$ of publication $i$ is produced by a constant elasticity of substitution (CES) production function with constant returns to scale (Arrow et al. 1961),

\footnotetext{
2 For an overview, see e.g., Cacioppo and Berntson (2005) and Cacioppo et al. (2006).
} 


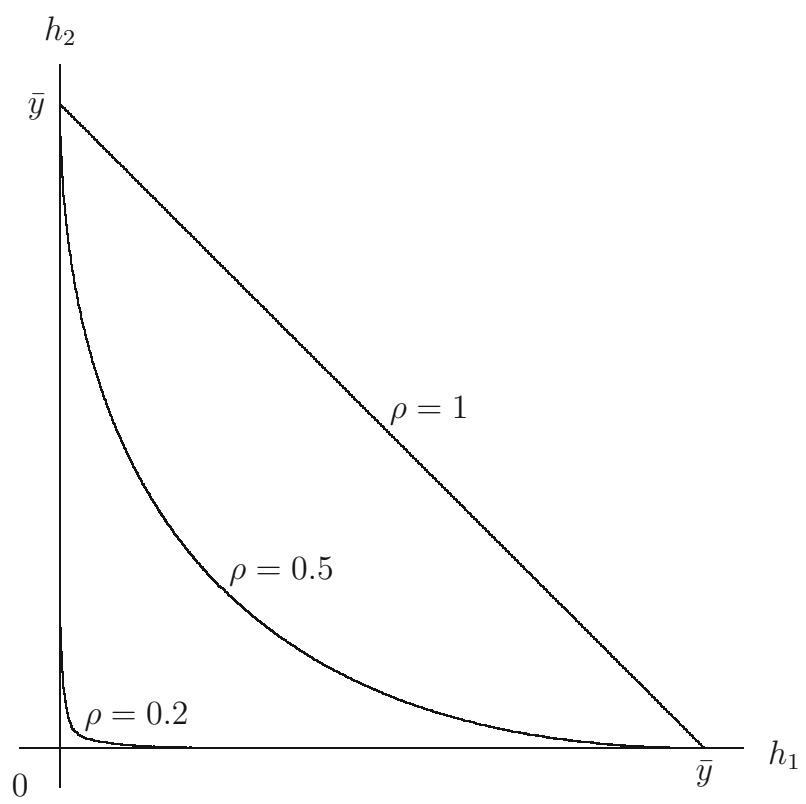

Fig. 1 The CES function for $\alpha+\beta>1$

$$
Y_{i}=A\left[\alpha H_{i 1}^{\rho_{i}}+\beta H_{i 2}^{\rho_{i}}\right]^{\frac{1}{\rho_{i}}}
$$

where $H_{i 1}$ and $H_{i 2}$ are human capital measures of the two co-authors. Since this is a production function with two inputs, these must be (price) substitutes with a positive elasticity of substitution between them, which in this case is $\sigma=\frac{1}{1-\rho}>0$, requiring that $\rho<1$. We have three special cases. For $\rho_{i} \longrightarrow-\infty$, output will be equal to $A \min \left\{H_{i 1}, H_{i 2}\right\}$, for $\rho_{i} \longrightarrow 0$ output will be $A H_{i 1}^{\frac{\alpha}{\alpha+\beta}} H_{i 2}^{\frac{\beta}{\alpha+\beta}}$, and for $\rho_{i}=1$, we have $Y_{i}=A\left[\alpha H_{i 1}+\beta H_{i 2}\right]$. It can be shown that the partial derivative of output $Y$ with respect to $\rho$ is negative, but that there is a discontinuity at $\rho=0$. Figure 1 visualizes input combinations for $\rho \in(0,1]$.

The idea will be that for given values of $A, H_{i 1}, H_{i 2}$, and $Y_{i}, \rho_{i}$ can be obtained through approximation. ${ }^{3}$ If the two inputs are complementary, the cross-derivative of the production function will be positive, $\frac{\partial^{2} Y_{i}}{\partial H_{i 1} \partial H_{i 2}}>0$, and in the case of substitutes, the cross-derivative will be zero (or negative), $\frac{\partial^{2} Y_{i}}{\partial H_{i 1} \partial H_{i 2}} \leq 0$. My objective is to distinguish between author combinations that are more or less complementary. For each article $i$, I will compute a $\rho_{i}$ in the range between 0 and 1 through approximation, indicating varying degrees of complementarity. The closer $\rho_{i}$ will be to 1 , the less complementary the human capital inputs of the two co-authors. To obtain $\rho_{i} \in(0,1], Y_{i}$ must be larger or equal to $A\left[H_{i 1}+H_{i 2}\right]$ for all observations $i$. I obtain this by setting $A=$

\footnotetext{
3 Note that the relative sizes of $\alpha$ and $\beta$ do not affect $\rho$. I set both, $\alpha$ and $\beta$, equal to one.
} 
$\min \left\{\frac{Y_{i}}{H_{i 1}+H_{i 2}}\right\}$. This way, I also make sure that the elasticity of substitution $\sigma=$ $1 /(1-\rho)$ will only assume values larger than unity.

The only inputs are the accumulated past (or yearly) publication records, used as proxies for the two authors' human capital stocks. This broad concept captures a wide range of productivity determinants such as ability, age, and incentives (unfortunately, I cannot measure time inputs). As the baseline version of the input provided by person $j$ in the production of article $i$, which was published in year $t$, I will thus use

$$
H_{i j}=\sum_{k=1}^{t-1}(1-\delta)^{t-k-1} Y_{j k},
$$

where $Y_{j k}=\sum_{h=1}^{\infty} Y_{h j k}$ is researcher $j$ 's output in year $k$ measured by the sum of the journal-quality measures of all publications $h$ in that year, ${ }^{4} \delta$ is a discount factor, and $k=1$ is the year of researcher $j$ 's first publication. Based on citation vintage, e.g., McDowell (1982) estimates that human capital of academic economists depreciates at rate 13.18. The approach is in line with the evidence that creative output typically rises toward middle age and falls thereafter (Galenson and Weinberg 2000; Jones 2010a).

A drawback of the above specification of human capital is that this measure is inverse U-shaped. It tends to increase with age with a maximum late in the researchers' careers. This feature penalizes younger researchers. Assume, for instance, that two talented, young scholars with short publication records and hence low $H_{i j}$ 's write a paper $i$ that appears in a highly ranked journal. $\rho_{i}$ has to be very low in that case to produce high output, indicating a high degree of complementarity. If ability were constant over life, then $\rho$ might be downward-biased simply because the authors have not had careers long enough to publish many articles in the past. Using $H_{i j}$ will also lead to imbalances in the human capital inputs of the two authors when the age difference is large. A number of studies suggest that input ratios should be balanced when inputs are complementary. ${ }^{5}$ In the context of this analysis, a higher degree of complementarity would be required to produce the same output if one author has a larger share of the combined human capital than if the shares are equal. Such imbalances are most likely when the age difference is large.

The following specification of human capital accommodates a possible downward bias of $\rho_{i}$ when at least one author is young,

$$
L_{i j}=\sum_{i^{\prime} \neq i} \frac{Y_{i^{\prime} j}}{2011-t_{1 j}},
$$

which is a scholar's average yearly career output excluding the publication of interest $i$ ( $t_{1 j}$ denotes the first year of $j$ 's career).

\footnotetext{
${ }^{4} \mathrm{I}$ account linearly for co-authorship for both, input and output variables, i.e., $Y_{i j}=Y_{i} / n_{i}$, where $n_{i}$ is the number of authors of article $i$.

5 See Prat (2002) for the composition of teams. Griliches (1969) made a related argument for physical and human capital.
} 


\section{Data}

The employed publication data were collected from EconLit by the Committee for Research Monitoring (CRM) of the German Economic Association. This database contains all journal articles authored or co-authored by all economists (including business researchers) affiliated with German, Austrian and (German-speaking) Swiss universities. German economists working abroad had to register themselves to be included. All individual researchers were granted access to their entries so that they could, if necessary, correct and complete their publication records. The data set, retrieved in May 2010, provides not only article characteristics, but also comprehensive and accurate background information on the authors.

In line with the production function outlined in Sect. 2, I used all articles with exactly two authors with active accounts in the database. This also excludes retired faculty. Articles that were published before 1969 were not included because EconLit, which is the major source of my data, started listing articles only in 1969. This restriction is not likely to bias my results since people who are still active in research in 2010 are not likely to have published much before 1969. Articles written by authors whose birth dates were unavailable were dropped. Note that for the CES production function (1), it is necessary that both authors have nonzero human capital as measured by Eq. (2). Hence, I only use articles whose authors have had positive output prior to publication. A larger sample is obtained when I use average yearly output over researchers' careers as human capital measure because, in that case, I do not need positive output in preceding years. The data set contains current affiliations, but it does not list complete employment histories.

Article quality $Y$ is measured by the CLm indicator (Combes and Linnemer 2010). CLm is based on a bibliometric two-step procedure. In a first step, all 304 EconLit journals which are also covered by the SSCI database were ranked using the indirect method. ${ }^{6}$ In a second step, Combes and Linnemer imputed quality indices for the remaining journals using the research performance of these journals' authors according to the SSCI journal publications and Google Scholar citations. This procedure results in a cardinal journal-quality index for all 1,168 journals indexed by EconLit. CLm can, therefore, be thought of as a more comprehensive alternative to impact factors. The CLm index does not reflect changes of a journal's quality over time. However, Combes and Linnemer's journal-quality weighting scheme is unique in the field of economics due to its comprehensiveness and its cardinal nature. Citation counts, which would allow to account for quality differences between articles that appeared in the same journal (Oswald 2007), are not available in my data base. However, in a different context, Azoulay et al. (2010) find effects of about the same magnitude independent of whether they use impact factors or citations to measure article quality (see Online Appendix $\mathrm{V}$ of their paper).

Table 2 provides descriptive statistics for the two benchmark data sets. The employed weighting scheme is CLm; for the value of $\delta$, I use two alternatives: (1) no human capital depreciation, i.e., $\delta=0$, and (2) $\delta=0.15$. I have 1,470 observations.

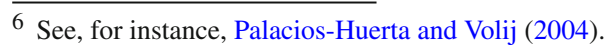


Table 2 Descriptive statistics

\begin{tabular}{lcccc}
\hline & Mean & SD & Min. & Max. \\
\hline$\rho$ with $\delta=0$ & 0.163 & 0.060 & 0.078 & 1 \\
$\rho$ with $\delta=0.15$ & 0.207 & 0.087 & 0.085 & 1 \\
Article quality $Y$ & 20.200 & 19.113 & 4.755 & 100 \\
$h_{1}$ (h.c. older) & 348.108 & 545.050 & 1.097 & $3,554.024$ \\
$h_{2}$ (h.c. younger) & 125.412 & 180.469 & 1.592 & $1,609.027$ \\
$h_{1} * h_{2}$ & $57,161.71$ & $145,787.4$ & 6.102 & $1,736,377$ \\
Average age (years) & 41.588 & 5.620 & 29.5 & 65 \\
Age difference (years) & 8.689 & 7.564 & 0.006 & 38.058 \\
Both female & 0.016 & 0.127 & 0 & 1 \\
Male/female & 0.118 & 0.322 & 0 & 1 \\
Business administration & 0.100 & 0.300 & 0 & 1 \\
Ba/econ & 0.076 & 0.265 & 0 & 1 \\
Preceding cooperations & 1.100 & 2.128 & 0 & 17 \\
\hline
\end{tabular}

Weighting scheme CLm; 1,470 observations

These articles were written by 825 different authors. The complementarity measures $\rho_{i}$ were computed by numerical methods (approximation) because Eq. (1) cannot be solved explicitly for $\rho$. The mean of $\rho$ is 0.2072 for $\delta=0.15$ and 0.1631 for $\delta=0$. The variance is also higher when $\delta=0.15$. At a first glance, it may be surprising that, on average, $\rho$ is lower when human capital does not depreciate. After all, article output $Y$ is the same in both cases, but $H_{1}$ and $H_{2}$ are higher when $\delta=0$. Hence, imputed complementarity of the inputs is smaller without human capital depreciation. The explanation is that the technology parameter $A$ is different in the two cases. This results from the adjustment $A=\min \left\{\frac{Y_{i}}{H_{i 1}+H_{i 2}}\right\}$ to normalize $\rho$ such that there is one observation which corresponds to perfect substitution, while for all others, we have varying degrees of complementarity.

The average age of the author pairs ranges from 29.5 to 65 years with a mean of 41.6years. The younger co-authors are between 23 and 64 years old, the older coauthors between 31 and 70. Collaborations between scholars of the same age are quite frequent in my sample. Indeed, the share of co-productions of authors of the same age appears to be even higher internationally according to earlier findings by Laband and Piette (1995). In my sample, $41.7 \%$ of all co-authorships involved scholars whose age difference was 5 years or less; in the sample examined in Laband and Piette (1995), it was more than $50 \%$. Of the articles, $62.7 \%$ were co-authored by authors whose age difference was 9 years or less; the respective share amounted for almost $75 \%$ in Laband and Piette (1995). These observations together with the large share of articles in my sample that involves younger co-authors in their late 20 s or early 30 s indicate that mentor-protégé collaborations between doctoral students and supervisors are somewhat more common among German economists than internationally. On average, the authors are around 8.7 years of age apart, the highest difference being slightly above 38 years. Note that the sample contains exact dates of birth rather than 
simply years of birth. Despite some measurement error, these exact birth dates were used to compute age differences.

Of all articles, $1.6 \%$ were written by two women, and in $11.8 \%$ of the cases, one author was female, the other male. Exactly ten percent of all articles were written by authors who both identified themselves as business administration researchers. Business administration, or "Betriebswirtschaftslehre," as it is called in German, comprises classical business fields such as finance and marketing as well as some microeconomic subjects like organizational theory. In the sample, $7.6 \%$ of the papers have mixed pairs of authors, one being an economist, the other one a business researcher. I have also computed the number of preceding collaborations. This variable measures how many articles have been co-authored by the two authors of paper $i$ up to the year before paper $i$ was published, the value ranges from 0 to 17 with a mean of 1.1 .

Combes and Linnemer (2010) have also provided the journal-quality scheme CLh which maintains the ordering of CLm but which is more convex, i.e., the quality weights of top journals compared to lower-ranked journals are higher in CLh than in CLm. I will use CLh for robustness checks. Other robustness checks will be performed using average yearly output $L_{i j}$ as human capital measure and different rates of human capital depreciation.

\section{Empirical analysis}

\subsection{Non-structural evidence}

Table 3 presents a first, non-structural look at how age affects complementarity in my sample. The dependent variable in these regressions is output CLm multiplied by 1,000. In specification (1), I regress output on human capital computed as in Eq. 2 with $\delta=0$. The coefficient on the cross-product of the human capital inputs, which is negative, captures complementarity. The share of variation in output quality explained by the model (the $R^{2}$ ) almost doubles when I include the age structure of the two collaborating authors in specification (2). The point estimates suggest that article quality is maximized if the authors are 28.4 years old on average, and if the age difference between the two is 5.9 years.

But, how does complementarity between the two authors' human capital inputs change with the age composition of the two collaborators? To address this question, I split the sample into three subgroups according to the age difference between the two collaborators: 0-6 years, 7-13 years, and 14 or more years. In specification (3), I include interaction terms of the cross-product of the human capital inputs with indicators for which of the three groups the authors in my sample belong to, using the 713 years as the control group: human capital inputs of authors with an age difference of more than 13 years are less complementary than human capital inputs of authors in the other two groups. Inclusion of additional control variables in specification (3) does not affect the coefficients of interest (the coefficients on these additional controls are shown in Appendix Table 11). These results suggest that the age structure of collaborating researchers is related to article quality, both directly and indirectly through human capital inputs. In the following section, I will examine this indirect relationship in more detail. 
Table 3 Non-structural estimates

\begin{tabular}{|c|c|c|c|c|}
\hline & (1) & (2) & (3) & (4) \\
\hline Constant & $\begin{array}{l}9,155.157 * * * \\
(912.367)\end{array}$ & $\begin{array}{l}558.253 \\
(9,574.501)\end{array}$ & $\begin{array}{l}483.149 \\
(9,801.215)\end{array}$ & $\begin{array}{l}1,711.638 \\
(9,750.774)\end{array}$ \\
\hline$H_{1}$ & $\begin{array}{l}1.682 * * \\
(0.724)\end{array}$ & $\begin{array}{l}4.922 * * * \\
(0.828)\end{array}$ & $\begin{array}{l}3.988 * * * \\
(0.826)\end{array}$ & $\begin{array}{l}3.775 * * * \\
(0.857)\end{array}$ \\
\hline $\mathrm{H}_{2}$ & $\begin{array}{l}12.625^{* * *} \\
(2.535)\end{array}$ & $\begin{array}{l}15.390 * * * \\
(2.567)\end{array}$ & $\begin{array}{l}13.309^{* * *} \\
(2.753)\end{array}$ & $\begin{array}{l}12.674 * * * \\
(2.804)\end{array}$ \\
\hline$H_{1} \cdot H_{2}$ & $\begin{array}{l}-0.008^{* *} \\
(0.003)\end{array}$ & $\begin{array}{l}-0.008^{* *} \\
(0.003)\end{array}$ & $\begin{array}{l}0.003 \\
(0.006)\end{array}$ & $\begin{array}{l}0.003 \\
(0.006)\end{array}$ \\
\hline Average age & & $\begin{array}{l}752.253^{*} \\
(439.573)\end{array}$ & $\begin{array}{l}786.779 * \\
(447.225)\end{array}$ & $\begin{array}{l}747.872 * \\
(445.018)\end{array}$ \\
\hline Average squared & & $\begin{array}{l}-13.256^{* * *} \\
(4.951)\end{array}$ & $\begin{array}{l}-13.937 * * * \\
(5.043)\end{array}$ & $\begin{array}{l}-13.494 * * * \\
(5.022)\end{array}$ \\
\hline Age difference & & $\begin{array}{l}126.941 \\
(97.414)\end{array}$ & & \\
\hline Difference squared & & $\begin{array}{l}-10.805 * * * \\
(3.728)\end{array}$ & & \\
\hline$I(d<7)$ & & & $\begin{array}{l}98.671 \\
(659.508)\end{array}$ & $\begin{array}{l}52.664 \\
(654.236)\end{array}$ \\
\hline$I(d>13)$ & & & $\begin{array}{l}-974.770 \\
(712.633)\end{array}$ & $\begin{array}{l}-795.934 \\
(706.681)\end{array}$ \\
\hline$I(d<7) \cdot H_{1} \cdot H_{2}$ & & & $\begin{array}{l}-0.003 \\
(0.007)\end{array}$ & $\begin{array}{l}-0.003 \\
(0.007)\end{array}$ \\
\hline$I(d>13) \cdot H_{1} \cdot H_{2}$ & & & $\begin{array}{l}-0.015^{* *} \\
(0.006)\end{array}$ & $\begin{array}{l}-0.016^{* * * *} \\
(0.006)\end{array}$ \\
\hline Additional controls & No & No & No & Yes \\
\hline $\mathrm{R}^{2}$ & 0.0677 & 0.1305 & 0.1329 & 0.1394 \\
\hline Observations & 1,470 & 1,470 & 1,470 & 1,470 \\
\hline
\end{tabular}

Dependent variable: CLm*1,000; OLS regression; $\delta=0$; robust standard errors in parentheses; *** $p<$ $0.01, * * p<0.05, * p<0.1$

\subsection{Structural evidence}

To structurally estimate the determinants of complementarity in scientific collaboration, I will use a linear regression equation,

$$
\rho_{i}=c+\lambda m_{i}+\chi m_{i}^{2}+\kappa d_{i}+\eta d_{i}^{2}+\psi^{\prime} w_{i}+\varepsilon_{i}
$$

where $m_{i}$ is the average age of the co-authors of paper $i, d_{i}$ is their age difference in absolute terms, $w_{i}$ is a vector of covariates, and $\varepsilon_{i}$ is an error term.

The dependent variable in Eq. (4) is $\rho_{i}$ from Eq. (1). This measure of complementarity was obtained by numerical approximation and was not estimated. Given the assumptions stated in Sect. 2, $\rho$ is exactly identified; in contrast to two-step estima- 
tion, no sampling error is involved in the complementarity parameter's computation. If the employed method were a two-step estimation procedure, the coefficients of interest would be biased (Murphy and Topel 1985). The regressions in this section are, however, more comparable to regressions in many other studies, in which the authors include an index derived from a set of variables (either from the same data set or from a different data set) in their regressions (on either the left-hand side or the right-hand side of the equation).

Table 4 shows the regression results for human capital depreciation rates of 15 and $0 \%$ per year. In both cases, the coefficients are pretty robust across specifications. In Specifications (1)-(4), the dependent variable is computed using $\delta=0.15$. The coefficients of interest are average age and age difference, as well as squared terms for average age and age difference. All these variables significantly affect the complementarity parameter $\rho$, the squared average age is significant only at the 10 percent level, all others at the 1 percent level. I also include dummies for gender and for the sub-disciplines in which the authors are active. Unreported results show that the coefficients that measure the impact of age composition hardly change if these controls are dropped. Specification (2) also controls for the years in which the articles were published. The coefficients on age difference and the squared term increase slightly in absolute value and become more significant. Specification (3) adds controls for the number of preceding collaborations. Again, inclusion of year dummies only slightly affects the coefficients of interest.

The age difference has a significantly negative effect on $\rho$, i.e., the larger the difference, the more complementary are the two authors' inputs. However, due to the positive coefficient on the squared term, this effect is reversed once a certain difference is reached. Based on specification (4) which includes the full set of regressors, $\rho$ is minimized, i.e., complementarity is maximized, if the age difference between the two authors is 10.39 years. Up to 65 years, a higher average age of the two co-authors means that their human capital inputs will be less complementary. This is plausible given the fact that, up to a certain age, older authors tend to have higher human capital endowments.

The coefficient of the gender dummies indicates that complementarity is increased if both co-authors are female. For mixed pairs, the effect is insignificant in most specifications and disappears once the number of preceding collaborations is controlled for. This confirms earlier findings by McDowell et al. (2006) who report significant gender differences in publication behavior. Although, in a given year, female economists are less likely to publish, conditional on publishing they are not less likely to have a co-author. ${ }^{7}$ And, even more importantly, women are not less likely than male economists to publish in the leading journals in economics. This is true in my sample as well. Articles that were authored by two women on average are of higher quality than articles written by two male authors. Human capital, on the other hand, is lower

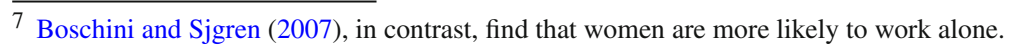




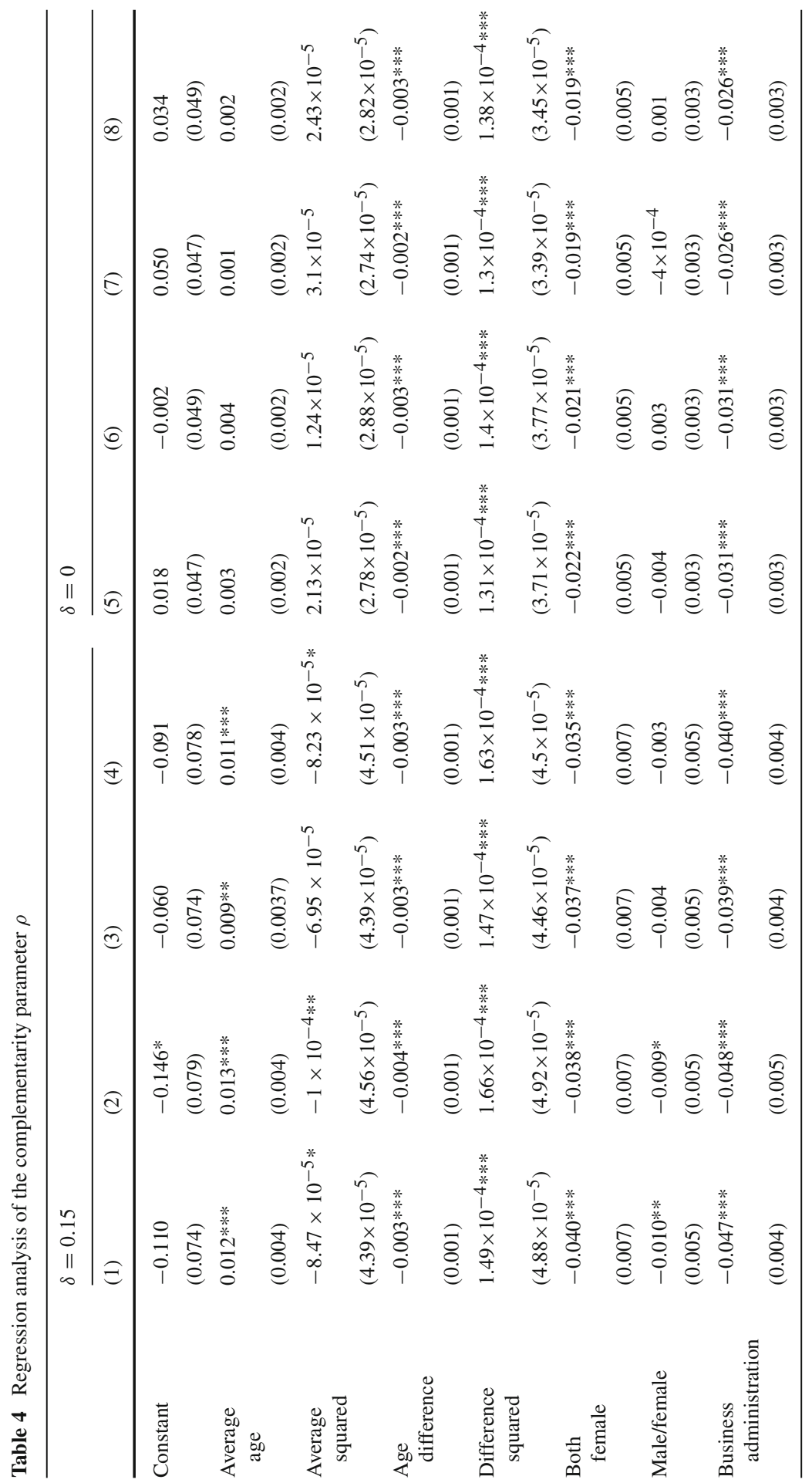




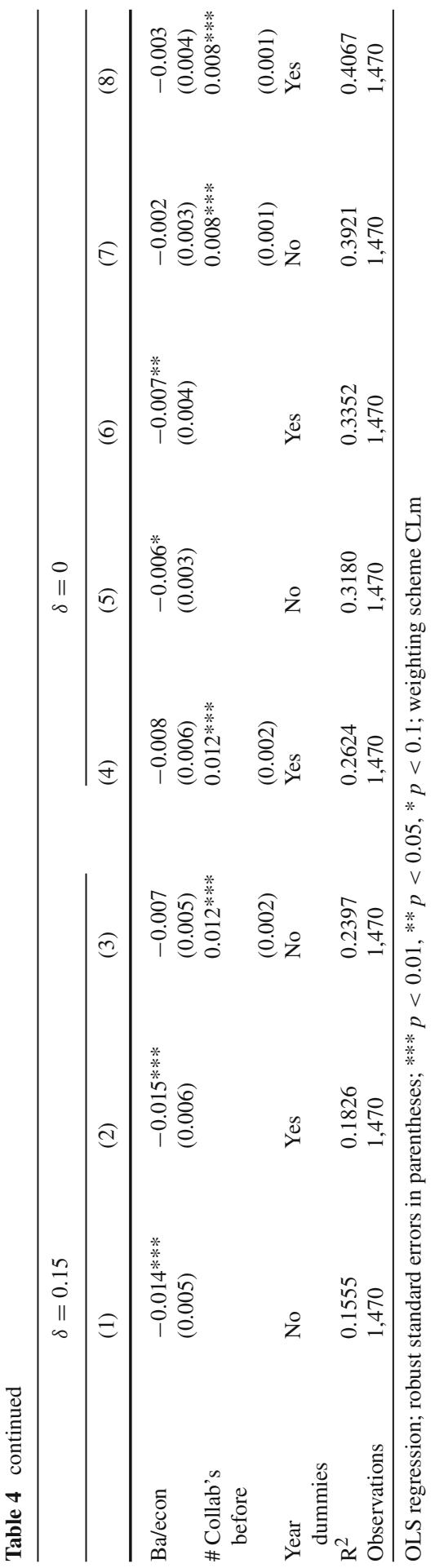


if both authors are female. ${ }^{8}$ Since men's human capital proxy is higher, less of their output will have to be explained by complementarity.

The coefficient on business co-authors is negative and statistically significant, too. Average article quality is lower if the business administration dummy equals one, but so is human capital of business researchers in my sample. Team work is often associated with increasing specialization. As knowledge accumulates, it becomes harder to attain the research frontier. As a consequence, scientists can either choose to learn more or to specialize on more narrow subjects (Jones 2009; Ductor 2014). Intellectual distance appears to affect complementarity in my sample as indicated by the highly significant coefficient on business administration. The fact that the coefficients of interest remain unaffected, however, suggests that intellectual distance is unrelated to the link between age and complementarity.

For the number of preceding collaborations, I obtain a positive coefficient suggesting diminishing returns to collaboration. This may seem surprising, since one would expect higher coordination costs during early collaborations. The preceding collaborations variable may, however, pick up consumption benefits of co-authorship (see Sect. 5.2). The observed positive relationship might as well reflect learning on the part of each co-author. The two specialists might learn each other reducing the net value of any future collaborations. Another possible explanation is that the authors write several papers at the same time, and the papers that appear later were rejected first and appeared in lower-ranked journals.

Specifications (5)-(8) repeat the analysis for $\delta=0$. Given that the McDowell (1982) estimate of $\delta=13.18 \%$ appears to be rather high, and it makes sense to compare estimates for different rates of human capital depreciation. The coefficients of average age and average age squared become insignificant. All other coefficients of interest remain virtually unchanged in terms of signs, magnitudes, and levels of significance. Complementarity is now highest if the age difference is 9.46 years when the full set of regressors is included. One thing, however, changes substantially. With $\delta=0$, the $R^{2}$ is higher across all specifications. When I control for the full set of regressors, it increases from 0.2624 with $\delta=0.15$ in specification (4) to 0.4067 with $\delta=0$ in specification (8).

Table 5 provides further robustness checks. In all specifications, I control for all available characteristics of articles and authors. If human capital is measured as in Eq. (3), i.e., by average output over the entire career, the sample size increases by 365 observations because output in previous years does not necessarily have to be positive. Average age now has a significantly negative effect on complementarity. This makes sense given that the human capital measure $L_{j}$ is not increasing with age. ${ }^{9}$ The coefficients on age difference and the control variables hardly change at all.

\footnotetext{
8 The gender differences in human capital are significant at a $5 \%$ level of significance, those on article output $y$ at the $10 \%$ level of significance. Average output of the 1,273 articles authored by two men is 10.1798 with a standard deviation of 9.7706 , and for the 24 articles authored by two women, the mean is 13.6980 with a standard deviation of 11.9885 . This yields a t test statistic for the gender difference of the averages of 1.74 .

9 Division by a linear term in years since the first article ignores that age-productivity profiles are quadratic (Oster and Hamermesh 1998; Rauber and Ursprung 2008).
} 


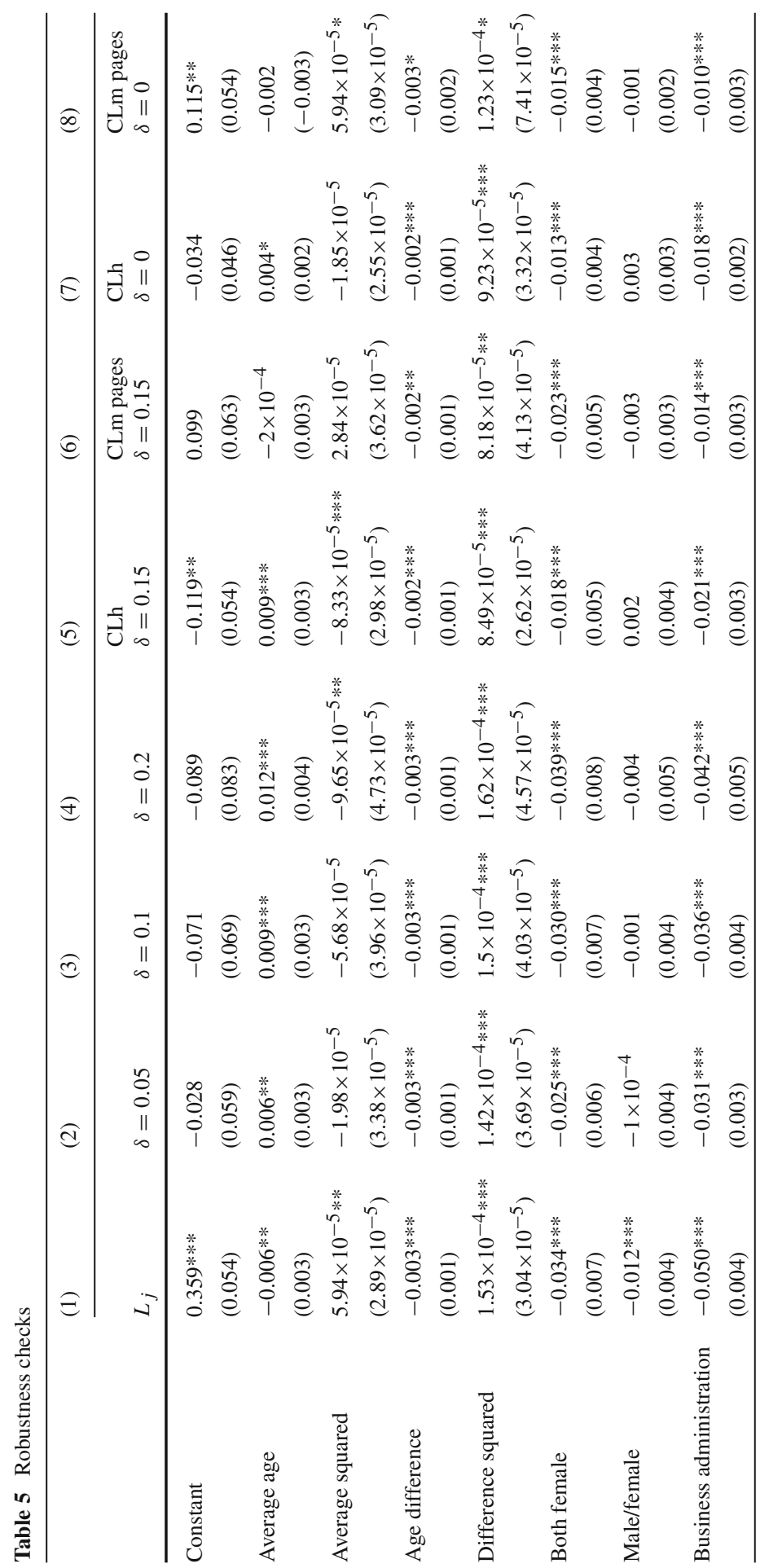




$$
\text { | }
$$


Columns (2)-(4) of Table 5 vary the rates of human capital depreciation. All that changes is the $R^{2}$ which increases as $\delta$ becomes lower. A human capital depreciation rate of $15 \%$ may thus be too high. The relationship between age and complementarity is practically unaffected by the way human capital is measured. In columns (5)-(8), different measures not only for human capital but also for article quality are used. Columns (5) and (7) show results if output is measured by the more convex scheme CLh for the baseline rates of human capital depreciation of 0 and $15 \%$. In columns (6) and (8), article output is measured by the product of CLm and article length in pages. The sample size is reduced when pages are taken into account because number of pages was not available for 130 publications that were in press when the data were retrieved. Again, the results are highly robust. All coefficients of interest have the same signs as before. Although they become somewhat smaller in absolute value, most of them remain significant at a $1 \%$ level of significance. In columns (6) and (8), the coefficients on age difference and the squared term are significant only at the 5 and $10 \%$ levels, respectively.

\section{A theory of complementarity}

This section presents two explanations for the link between age and complementarity. Specialization and learning are not taken into account: Ductor (2014) has already shown that the authors' fields of specialization (as measured by JEL codes in their other work) matter for co-authorship formation. In my sample, however, specialization proxied by business administration and economics seems unrelated to how age affects complementarity. Learning does not appear to be an issue either. If, over the course of their careers, authors were to observe that they are most productive when working with collaborators who are 10 years younger or older, one would expect age difference of their co-authors to converge to 10 years as scholars get older. Unreported results show that it does not: controlling for individual fixed effects, authors tend to collaborate with scholars that are farther away in terms of age as they get older. Age difference is not only increasing with the authors' age, it also diverges away from the optimal level of 10 years. ${ }^{10}$

\subsection{Age-specific skill heterogeneity}

The decision to collaborate is often made jointly. However, I will illustrate my interpretation of $\rho$ by providing an example in which one economist searches for a collaborator. This conceptual scholar has an idea, say a concept for a new model. He knows that he needs a collaborator to solve the model. I will refer to this collaborator as the technical scholar. He meets a colleague, say at a conference, and they agree to collaborate. The conceptual scholar does not know with certainty whether his and the collaborator's skills match and their joint project will be successful. But in the following, I will

\footnotetext{
10 This may be due to the age structure in the profession. If professors always collaborate with graduate students, the age difference will necessarily increase as they get older on average, even if they know about the optimal age difference.
} 
argue that he can use the collaborator's age or the difference between his own and the collaborator's age as an indicator for skill match. The probability of a skill match $s$ can be thought of as being equal to $1-\rho$, where $\rho$ is a function of age difference and average age as in Eq. (4).

Cognitive skills may be one channel through which age affects human capital complementarity. To establish this link formally, one may assume that the complementarity parameter $\rho$ is a function of skills that are not reflected by our human capital measures. These can be thought of as different methods and approaches to do research. Anecdotal evidence suggests that when two researchers of different age collaborate, the younger scholar tends to perform technical tasks such as detailed computations and programming, whereas the older scholar is responsible for the overall concept. I use this as a starting point and assume that each individual has technical skills $T(a)$ which decrease with age $a$ and conceptual skills $C(a)$ which increase over the life cycle. The two skill could follow, for instance, logistic patterns as in Jones (2010a).

Technical skills capture an individual's ability to handle complicated theoretical setups and complex econometric techniques; in particular, tools and techniques that were not known to previous generations. Conceptual skills comprise everything that is related to the accumulation of knowledge. Acquisition of experience implies increased conceptual skills. The complementarity parameter $\rho$ can then be modeled as a function of how abilities of the two collaborating researchers interact with complementarity being the product of conceptual and technical skills of the two co-authors. Since $\rho$ is decreasing in complementarity, one can write

$$
\rho=1-C\left(a_{1}\right) \cdot C\left(a_{2}\right) \cdot T\left(a_{1}\right) \cdot T\left(a_{2}\right)=1-C\left(a_{1}\right) \cdot C\left(a_{1}-d\right) \cdot T\left(a_{1}\right) \cdot T\left(a_{1}-d\right),
$$

where the sub-index $j=1$ indicates the older of the two researchers and $j=2$ is his younger colleague. The conceptual scholar's problem is then to minimize $\rho$ over $a_{2}$ for given $a_{1}$ or, equivalently, to derive an optimal age difference $d^{*}$.

This framework is related to the concept of fluid and crystallized intelligence suggested by the noted psychologist Raymond Cattell and to David Galenson's theory of old masters and young geniuses. Cattell (see Cattell 1963; Horn and Cattell 1966) distinguishes between fluid intelligence which is hereditary and crystallized intelligence which captures all skills that are due to an individual's education and experience. An individual's ability to acquire knowledge, i.e., fluid intelligence, is highest when someone is young, whereas knowledge itself, i.e., crystallized intelligence, increases over time. The two factors are, of course, related to each other: someone with a high capacity to learn learns more and learns faster. This may also apply to technical and conceptual skills, and the best technicians may turn into the best conceptualists.

Galenson (see Galenson 2006; Galenson and Weinberg 2000, 2001) divides artists (painters, novelists, and movie directors) into two categories. Artists belonging to category one, which he labels conceptual, attain their greatest achievements at a relatively young age. Picasso belongs to this group. Galenson describes the working style of conceptual artists as being characterized by long periods of advance planning. The actual working process in which a painting comes to existence, however, is rather short. Experimental artists like Cézanne, on the other hand, are most productive at a relatively older age. According to Galenson, experimental painters rarely have elab- 
orate plans in mind when they start painting. Work on a particular painting may take an experimental painter many years.

A similar approach can be found in Jones (2010a) who observes that, at the beginning of the twentieth century, Nobel Laureates and great inventors were between 5 and 8 years younger at the time of their scientific achievements, than 100 years later. He introduces early life cycle effects and late life cycle effects. Early life cycle effects depend on the point in time at which researchers complete formal education. Late life effects capture that part of an individual's innovation potential which is not related to education. Jones finds empirical support for the assumption that people's ability to produce scientific breakthroughs is declining as they get older implying a negative slope for late life effects. While the late life effects have remained stable over the course of the twentieth century, due to an accumulation of knowledge, it has taken scholars longer to obtain their highest degrees and, hence, to achieve the research frontier. According to Jones, the fact that researchers have to learn longer during the period in which their raw ability to innovate is highest has reduced scientific output.

I put Galenson's labeling on its head by referring to the skill that increases over life as conceptual. Galenson's analysis only considers some of the most outstanding geniuses in the history of art, whereas my data set includes the works of all academic economists working in Germany, Austria, and Switzerland as well as some German-speaking scholars working abroad. At most a handful of the individuals in my sample fit into Galenson's genius category. The conceptual ability includes not only having good ideas but also knowledge of the research process which requires some experience. Although Galenson discusses the possibility that painters may change during their careers from being conceptual artists to experimental artists who make important contributions in both approaches, he mostly treats the two types as mutually exclusive.

\subsection{Interpersonal relationships}

Another channel through which the age pattern may drive complementarity is the relationship between the two co-authors. This idea was first introduced in Hamermesh and Oster (2002). In their model, productivity is not the sole purpose of collaboration. People may also work together because they enjoy interacting with each other. Research may then create two streams of benefits: research output and consumption benefits realized during the production process. Hence, scholars seek to maximize a utility function $U\left(Y_{j}, c_{j}\right)$, where $j$ is a potential co-author, $Y$ is the research output, and $c$ is the consumption stream.

Hamermesh and Oster (2002) investigated how the decline in communication costs experienced over the last decades of the twentieth century affected research behavior and productivity. Distant co-authorship generates additional costs compared to other forms of research. If scholars were only interested in producing superior research, one would expect distant co-authored research to be more productive than other types of research. This conjecture turns out not to find support in their data. The consumption benefits model, in contrast, can explain the observed patterns. Answers to a survey conducted by Hamermesh and Oster suggest that distant co-authorship is positively correlated with friendship. There may be reasons to believe that friendship is related to 
age. As suggested by Hamermesh and Oster (2002), many lasting friendships between fellow economists develop in graduate school and involve peers of the same age group. If personal interactions between friends take away time from research production, this implies that the time input of a pair of co-authors becomes more complementary with increasing age difference.

A second effect, which works in the same direction, relates to competition. Especially in early phases of their careers, researchers from the same age group are likely to be competitors on the job market. Competition is, of course, not restricted to the job market. Science is, after all, an inherently competitive game. True scientists seek challenges and are inspired and motivated by competition. And when it comes to choosing their peer group, scientists are likely to consider their relative positions within their age category. Competition may harm collaboration between scientists, even though it is in both their interests to produce as good a paper as possible. The above framework with one conceptual and one technical scholar implies a hierarchical team structure. If the age difference between the two co-authors becomes smaller, the younger co-author may not accept this division of labor because the collaborator becomes a competitor and both co-authors may want to prove that they are smarter than the other one.

A "common paradigm effect" may countervail the positive relation between age difference and complementarity. Economics is a relatively new discipline which has, over time, undergone substantial transitions. Collaborating scholars need to share some common paradigm as a starting point for their communication, especially with respect to the method of investigation. This argument is less related to changes in topics that are considered en vogue within the profession-researchers with different interests rarely collaborate anyway (Fafchamps et al. 2010) - than to changes in the techniques that are employed. The common paradigm effect may be more of an issue at universities in Germany, Austria, and Switzerland, where professors often are the employers of their younger collaborators. If, say, a senior professor with an institutionalist background hires a junior with a lot of quantitative training it may well be the case that their work suffers. Taken together, consumption benefits, competition, and common paradigm can also give rise to an optimal age difference between two co-authors.

\section{Survey-based analysis}

In summer 2011, I conducted a survey with the objective to test the theories presented in the previous section. I drew a sample from the 1,470 articles in my data set and asked the authors of these articles about the collaboration process with their co-authors. The sample was constructed to maximize the number of possible respondents. Each researcher was asked only about one publication and the questionnaire was always sent to both authors of an article. It turned out that I was not able to send the questionnaire to authors affiliated with institutions outside Germany, Austria, or Switzerland; so for some papers, I could send the questionnaire only to one author. Details about the administration of the survey with additional descriptive statistics can be found in Appendix 1.

To quantify their conceptual and technical skills, I asked the authors how much they contributed to the research concept, how much of the technical tasks they per- 
formed, and about their share in writing up the article. To test the explanation based on interpersonal relationships, I asked the authors whether they were already friends with their co-authors when they started working on the project, whether they became friends during that process, or whether their relationship was purely professional. I also asked the two co-authors whether they ever applied for the same jobs. The answer to this question serves as a proxy for competition between the two collaborators. Note that the age difference is now defined as the age of the respondent minus the age of the co-author. It can, therefore, assume negative values.

Table 6 compares the arithmetic means of the responses of the two collaborators. The modal response was $50 \%$ for all tasks. The difference in shares of contributions between older and younger author is most pronounced for technical execution of the project. I also calculated a measure of the shares in the three tasks relative to the average contribution. For this measure, I first computed the arithmetic mean of the three shares for every respondent and then divided each share by this arithmetic mean. This measure accounts for the fact that an author may have had a higher or lower overall share in the realization of an article. In other words, even if an author said

Table 6 Survey data: descriptive statistics

\begin{tabular}{|c|c|c|c|}
\hline & All respondents & Older author & Younger author \\
\hline Same institution & $0.6613(313)$ & $0.6582(158)$ & $0.6645(155)$ \\
\hline Different institution $(<100 \mathrm{~km})$ & $0.0703(313)$ & $0.0633(158)$ & $0.0774(155)$ \\
\hline Different institution $(>100 \mathrm{~km})$ & $0.2684(313)$ & $0.2785(158)$ & $0.2581(155)$ \\
\hline Own share concept & $50.75(308)$ & $51.62(154)$ & $49.87(154)$ \\
\hline Own share tech tasks & $50.58(308)$ & $44.74(154)$ & $56.43(154)$ \\
\hline Own share writing & $51.07(308)$ & $48.90(154)$ & $53.25(154)$ \\
\hline Idea rel. to av. contribution & $1.0034(308)$ & $1.0760(154)$ & $0.9307(154)$ \\
\hline Tech rel. to av. contribution & $0.9900(308)$ & $0.9152(154)$ & $1.0648(154)$ \\
\hline Writing rel. to av. contribution & $1.0083(308)$ & $1.0120(154)$ & $1.0045(154)$ \\
\hline Met $>3 y$ before collaboration & $0.6804(316)$ & $0.7063(160)$ & $0.6535(156)$ \\
\hline Met $<3 y$ before collaboration & $0.3006(316)$ & $0.2750(160)$ & $0.3269(156)$ \\
\hline Not met before collaboration & $0.0190(316)$ & $0.0188(160)$ & $0.0192(156)$ \\
\hline Colleagues/fellow students & $0.4684(301)$ & $0.5098(153)$ & $0.4257(148)$ \\
\hline Mentor-protégé relation & $0.3389(301)$ & $0.3203(153)$ & $0.3581(148)$ \\
\hline Met at a conference & $0.1063(301)$ & $0.0915(153)$ & $0.1216(148)$ \\
\hline Contacted to collaborate & $0.0864(301)$ & $0.0784(153)$ & $0.0946(148)$ \\
\hline Were friends before & $0.6181(309)$ & $0.6795(156)$ & $0.5556(153)$ \\
\hline Became friends & $0.1812(309)$ & $0.1538(156)$ & $0.2092(153)$ \\
\hline Purely professional & $0.2006(309)$ & $0.1667(156)$ & $0.2353(153)$ \\
\hline Ever applied for same jobs & $0.1529(314)$ & $0.1635(159)$ & $0.1419(155)$ \\
\hline Never applied for same jobs & $0.7038(314)$ & $0.6667(159)$ & $0.7419(155)$ \\
\hline Do not know & $0.1433(314)$ & $0.1698(159)$ & $0.1161(155)$ \\
\hline
\end{tabular}

Number of respondents in parentheses next to relative frequencies. 317 responses received in total (rate $54.75 \%)$ 
Table 7 Concept, technique, writing, and age

\begin{tabular}{|c|c|c|c|c|c|c|}
\hline \multirow{2}{*}{$\begin{array}{l}\text { Dependent } \\
\text { variable }\end{array}$} & (1) & (2) & (3) & (4) & (5) & (6) \\
\hline & Share concept & Rel.concept & Share tech & Rel. tech & Share writing & Rel. writing \\
\hline \multicolumn{7}{|l|}{ All respondents } \\
\hline \multirow[t]{2}{*}{ Own age } & 0.292 & -0.001 & 0.291 & 0.002 & 0.193 & -0.001 \\
\hline & $(0.312)$ & $(0.005)$ & $(0.291)$ & $(0.005)$ & $(0.261)$ & $(0.004)$ \\
\hline \multirow[t]{2}{*}{ Age difference } & 0.044 & $0.010 * *$ & $-0.744 * * *$ & $-0.008 *$ & $-0.467 * *$ & -0.002 \\
\hline & $(0.253)$ & $(0.004)$ & $(0.226)$ & $(0.004)$ & $(0.223)$ & $(0.003)$ \\
\hline Controls & Yes & Yes & Yes & Yes & Yes & Yes \\
\hline $\mathrm{R}^{2}$ & 0.1224 & 0.2160 & 0.2484 & 0.2266 & 0.1959 & 0.1744 \\
\hline Observations & 289 & 289 & 289 & 289 & 289 & 289 \\
\hline \multicolumn{7}{|l|}{ Older authors } \\
\hline \multirow[t]{2}{*}{ Own age } & -0.430 & $-0.018^{* *}$ & $0.723 *$ & 0.013 & 0.407 & 0.005 \\
\hline & $(0.508)$ & $(0.009)$ & $(0.428)$ & $(0.010)$ & $(0.362)$ & $(0.005)$ \\
\hline \multirow[t]{2}{*}{ Age difference } & $1.064 *$ & $0.031 * * *$ & $-1.107 * *$ & $-0.021^{*}$ & $-0.752^{*}$ & $-0.012 *$ \\
\hline & $(0.565)$ & $(0.010)$ & $(0.510)$ & $(0.011)$ & $(0.431)$ & $(0.006)$ \\
\hline Controls & Yes & Yes & Yes & Yes & Yes & Yes \\
\hline $\mathrm{R}^{2}$ & 0.3408 & 0.4461 & 0.4340 & 0.4545 & 0.3856 & 0.4125 \\
\hline Observations & 144 & 144 & 144 & 144 & 144 & 144 \\
\hline \multicolumn{7}{|l|}{ Younger authors } \\
\hline \multirow[t]{2}{*}{ Own age } & 0.697 & 0.008 & 0.140 & -0.002 & 0.014 & -0.005 \\
\hline & $(0.504)$ & $(0.007)$ & $(0.465)$ & $(0.008)$ & $(0.452)$ & $(0.008)$ \\
\hline \multirow[t]{2}{*}{ Age difference } & -0.564 & -0.004 & 0.013 & 0.010 & $-0.759 *$ & -0.006 \\
\hline & $(0.586)$ & $(0.008)$ & $(0.446)$ & $(0.007)$ & $(0.404)$ & $(0.007)$ \\
\hline Controls & Yes & Yes & Yes & Yes & Yes & Yes \\
\hline $\mathrm{R}^{2}$ & 0.2855 & 0.3783 & 0.3294 & 0.3404 & 0.2912 & 0.3083 \\
\hline Observations & 145 & 145 & 145 & 145 & 145 & 145 \\
\hline
\end{tabular}

OLS regression; robust standard errors in parentheses; additional controls include indicators for respondent and co-author being female or economists, respectively, their human capital endowments, the article score CLm, indicators for distance during collaboration, how long the authors knew each other and how their collaboration started, as well as year and country dummies

$* * * p<0.01, * * p<0.05, * p<0.1$

that $30 \%$ of the idea of a project were his, this may be high relative to his overall contribution if he says he performed only $10 \%$ of the technical tasks and of writing up the result.

Table 7 shows tests of the skill heterogeneity theory presented in Sect. 5.1. The upper panel includes all respondents, whereas the middle panel only considers the older coauthors, and the lower panel only considers younger co-authors. An author's share of the concept does not increase with the age difference. However, relative to the overall contribution, older scholars have contributed more conceptually, because older authors tend to contribute less overall relative to their younger collaborators. The correlation between an author's share of the technical execution and the difference between his 
Table 8 Job market competition, friendship, and age

\begin{tabular}{|c|c|c|c|c|}
\hline \multirow[t]{2}{*}{ Dependent variable } & (1) & (2) & (3) & (4) \\
\hline & Were friends & Were/became & Competed & Cannot exclude \\
\hline \multicolumn{5}{|l|}{ All respondents } \\
\hline Own age & $\begin{array}{l}-0.058 * * * \\
(0.017)\end{array}$ & $\begin{array}{l}-0.066 * * * \\
(0.019)\end{array}$ & $\begin{array}{l}-0.048^{* *} \\
(0.021)\end{array}$ & $\begin{array}{l}-0.046^{* *} \\
(0.019)\end{array}$ \\
\hline Age difference & $\begin{array}{l}0.048 * * * \\
(0.013)\end{array}$ & $\begin{array}{l}0.047 * * * \\
(0.014)\end{array}$ & $\begin{array}{l}0.030 * * \\
(0.014)\end{array}$ & $\begin{array}{l}0.030 * * \\
(0.013)\end{array}$ \\
\hline Controls & Yes & Yes & Yes & Yes \\
\hline Pseudo- $\mathrm{R}^{2}$ & 0.2204 & 0.2072 & 0.1179 & 0.1084 \\
\hline \multicolumn{5}{|l|}{ Older authors } \\
\hline Own age & $\begin{array}{l}0.024 \\
(0.030)\end{array}$ & $\begin{array}{c}-0.003 \\
(0.030)\end{array}$ & $\begin{array}{l}-0.007 \\
(0.028)\end{array}$ & $\begin{array}{l}-0.016 \\
(0.027)\end{array}$ \\
\hline Age difference & $\begin{array}{l}-0.116 * * * \\
(0.035)\end{array}$ & $\begin{array}{l}-0.086^{* *} \\
(0.037)\end{array}$ & $\begin{array}{l}-0.129 * * * \\
(0.042)\end{array}$ & $\begin{array}{l}-0.094 * * * \\
(0.033)\end{array}$ \\
\hline Controls & Yes & Yes & Yes & Yes \\
\hline Pseudo- $\mathrm{R}^{2}$ & 0.3350 & 0.2931 & 0.2675 & 0.2389 \\
\hline Observations & 145 & 145 & 148 & 148 \\
\hline \multicolumn{5}{|l|}{ Younger authors } \\
\hline Own age & $\begin{array}{l}-0.048 \\
(0.030)\end{array}$ & $\begin{array}{l}-0.071^{*} \\
(0.037)\end{array}$ & $\begin{array}{l}-0.038 \\
(0.034)\end{array}$ & $\begin{array}{l}-0.002 \\
(0.031)\end{array}$ \\
\hline Age difference & $\begin{array}{l}0.092 * * * \\
(0.030)\end{array}$ & $\begin{array}{l}0.114 * * * \\
(0.028)\end{array}$ & $\begin{array}{l}0.114 * * * \\
(0.037)\end{array}$ & $\begin{array}{l}0.095 * * * \\
(0.029)\end{array}$ \\
\hline Controls & Yes & Yes & Yes & Yes \\
\hline Pseudo- $\mathrm{R}^{2}$ & 0.2773 & 0.3151 & 0.2166 & 0.2044 \\
\hline Observations & 144 & 135 & 132 & 146 \\
\hline
\end{tabular}

Probit estimates; robust standard errors in parentheses; additional controls include indicators for respondent and co-author being female or economists, respectively, their human capital endowments, the article score CLm, indicators for distance during collaboration, how long the authors knew each other and how their collaboration started, as well as country dummies; other than before, year of publication was accounted for linearly

$* * * p<0.01, * * p<0.05, * p<0.1$

and his co-author's age is negative. The same applies to the share of writing the report. In Sect. 5.1, it was argued that conceptual skills were increasing with an author's age, whereas technical skills were decreasing with age. Most coefficients of the age variable are insignificant. But, this is in line with the model because, conditionally on age difference, the co-author's age increases with own age, too.

Table 8 shows tests of the theory of personal relationships. In column (1), a dummy indicating whether the respondent said that he and his co-author were friends when they started working on the project is regressed on the respondent's age, the difference between his and his co-author's age, and various covariates. The coefficient on own age is significantly negative and the coefficient on age difference is significantly positive when the whole sample is used. More informative are the middle and lower panels, which divide the sample into older and younger authors. For older authors, age difference is positive; for younger authors, it is negative. In both subsamples, the coefficients on age difference are significantly different from zero. When older authors are taken into consideration, the coefficient is negative, and for younger authors it is 
positive. Even though the coefficients have different signs, the picture is the same: the smaller the age difference, the more likely the two authors were friends before they started their collaboration. In column (2), the dependent variable is equal to 1 if the authors were either friends before they started working on their joint project or if they became friends in the process. The coefficients are smaller in absolute value for older authors and larger in absolute value for younger authors than in column (1). This finding indicates that younger authors are more likely to say they became friends while they collaborated with their colleagues than older authors if they were not already friends in the first place.

Columns (3) and (4) repeat this analysis for indicators for whether the respondent and his co-author have ever applied for the same job or whether the respondent could not to exclude the possibility that they had ever applied for the same job. ${ }^{11}$ Again, I find that the smaller the age difference, the more likely it is that the two authors have ever competed on the job market. The survey, therefore, shows that personal relationships vary with the age composition of collaborating researchers. However, it remains an open question how exactly this affects the process of their joint research.

Table 12 in Appendix 2 shows the coefficients on the covariates from the regressions of the shares in the three tasks when the entire sample was used (upper panel of columns (1), (3), and (5) in Table 7) and the dummies indicating whether the authors had already been friends before their collaboration when the entire sample was used (upper panel of columns (1) and (3) in Table 8). One notable and intuitive result is that mentorprotégé relationships tend to reduce the probability that the two collaborators were friends before they started working together.

\section{Conclusion}

Jones (2010b) identifies two major trends in science: important innovations are made increasingly later in a scientist's life and by teams rather than solo researchers. Age and team work are, therefore, of prime interest in the economics of science, and this study demonstrates that the two must not be analyzed in isolation. It investigates the relation between age composition of collaborators and the complementarity of their inputs. It suggests an optimal age difference between co-authors of about 10 years. This result is highly significant and robust to the way research output and human capital are measured.

To be sure, the assumptions underlying the analysis in this study are rather restrictive. I do not estimate the production function, I simply assume that it is of a CES type. Neither do I estimate the complementarity parameter $\rho$. Based on my assumptions concerning production of knowledge, I obtain it by solving a simple production equation. Furthermore, collaboration between exactly two researchers is only a subset of all teamwork in economics, although by far the most frequent one. ${ }^{12}$ But, age

\footnotetext{
11 In column (4), the dependent variable is equal to 1 if the respondent either checked that he and the co-author have ever applied for the same job or if he checked that he did not know.

127,700 of the 19,606 articles used in Table 1 were single-authored. 8,095, i.e., $68 \%$, of the remaining 11,906 co-authored articles had exactly two authors.
} 
difference has a different meaning when more than two researchers collaborate. The exclusion of researchers whose birth dates were not available is another potential source of bias, but it is not clear in which direction this bias would go. Finally, given the institutional setting in the German-speaking area, I might get different results if I looked at researchers from other countries.

A major shortcoming of the presented analysis is that my sample only includes collaborations that actually lead to published results. Although most researchers submit their working papers until they eventually find an outlet, some papers actually end up in the waste bin. It is not clear whether and how such failure might be correlated with the age structure of the team. However, such a correlation would induce an estimation bias. One possibility to solve this problem would be to use data from RePEc (Research Papers in Economics), which links publications with earlier working paper versions if the title and at least one author are identical. However, most of the personal background characteristics that I controlled for in my analysis are not available from RePEc. Moreover, I might have misclassified many working papers as "unpublished" if I had used RePEc data, because titles often change during different rounds of revisions. Finally, such a study that uses RePEc data would still overlook all research that does not even lead to working papers. Even if I were able to control for all failed collaborations, there would still be a selection problem due to co-authorship formation. The average age difference in my sample is pretty close to 10 years, which suggests that authors may understand the link between age composition and productivity.

The findings presented in this paper may have implications for the way we think about scientific collaboration. Some portion of co-authorship may be motivated by friendship, which is correlated with age difference, and better technology has lowered the cost of collaborating with friends. But it is likely that the lure of productivity gains has also contributed to the dramatic increase in the observed rate of co-authorship. Being able to identify non-random elements of those productivity gains, therefore, becomes of great interest. This paper's findings suggest that the characteristics of coauthored work may be deliberately chosen to deal with increasing information overload (Jones 2010a). I use age difference as a proxy for sets of skills like conceptual skills and technical skills that make the scientific fruits of the collaboration greater than the sum of the individual inputs. It is these skill sets that ultimately are of more interest than the age difference per se. I would, therefore, not argue that, based on my findings, funding agencies should impose 'age mix' requirements for funding applications or that researchers looking for collaborators should only look at age difference with potential co-authors. The formation of research teams should involve researchers who have different skills. It may, however, help to keep in mind that age difference is a useful proxy for different skills.

Acknowledgments I am grateful to Lorenzo Ductor, Daniel Hamermesh, Robert Hofmeister, Winfried Pohlmeier, Heinrich Ursprung, the Editor Bernd Fitzenberger, an associate editor and two referees, as well as participants of presentations at the University of Konstanz, the EEA conference in Oslo 2011, UT Austin and the University of Vienna for helpful comments and discussions. Tobias Locher, Carl Maier, and Fabian Zintgraf provided excellent research assistance. 


\section{Appendix 1: The survey}

The survey used in Sect. 6 was conducted via mail in June 2011. I sent the questionnaire to 579 economists and business researchers. Among these scientists, 434 were affiliated with German, 72 with Austrian, and 73 with Swiss institutions. I picked a random sample of pairs from the original sample. Each individual researcher was asked about one paper only. Initially, it was intended to ask researchers outside Germany, Austria, and Switzerland, too. However, this idea had to be abandoned for organizational reasons, which is why not always both co-authors received the questionnaires.

The survey participants were not informed that the aim of the study was to relate their answers to the age structure of the collaborating pair. People may have suspected that the survey would be used to investigate plagiarism, e.g., professors letting their students do all the work and then publishing under their own name, which might have reduced the response rate. In order to avoid this, the survey informed all scholars that their co-authors were asked the same questions.

Each letter contained one sheet of paper with a cover letter on the front and the questionnaire on the back and a stamped and self-addressed envelope for the reply. The survey was administered in Germany via the University of Konstanz, in Switzerland via the Thurgauer Wirtschaftsinstitut (TWI), which is located in Kreuzlingen, Switzerland but part of the University of Konstanz and in Austria via the University of Vienna. The survey was sent out in early June 2011; responses were received until mid-August 2011.

The cover letter read as follows:

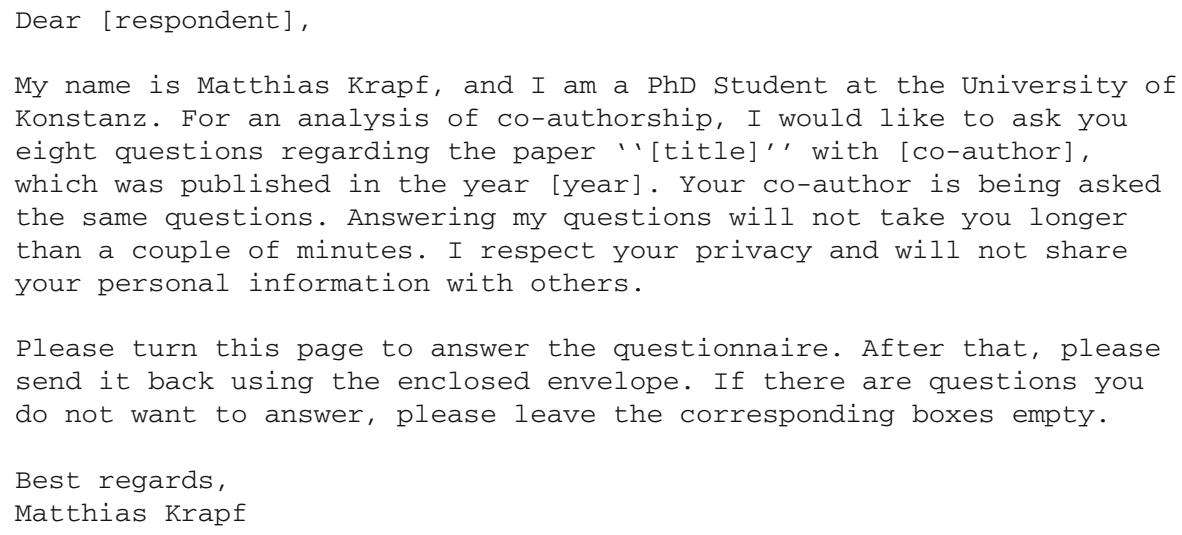

The questionnaire contained eight questions which could be answered by checking the corresponding boxes. To avoid going too much into the intimate details of their personal relations, people were only asked to distinguish between their relationship being purely professional or friendship. 
1. The process of writing the article

1.1 When we were writing the paper...

a) ...we were both at the same institution

b) ...we were at different institutions but within $100 \mathrm{~km}$ from each other

c) ...we were at different institutions and more than $100 \mathrm{~km}$ from each other

2. Individual Contributions

2.1 How much of the idea that lead to the article was yours or your co-author's?

2.2 How much of the technical tasks did you and your co-author perform?

2.3 Who wrote the paper down?

(for questions 2.1 to 2.3 eleven possible answers were given from 100 percent mine/0 percent co-author's to 0 percent mine/100 percent co-author's in steps of ten percentage points)

3.1 When have you first met your co-author?

a) More than 3 years before we started working on the paper

b) Up to 3 years before we started working on the paper

c) The decision to collaborate was made when/before we first met

3.2 How did your collaboration begin?

a) We were fellow students, e.g., in grad school, or colleagues at the same institution

b) We were in a mentor--prot $\backslash^{\prime}\{e\} g \backslash^{\prime}\{e\}$ relation

c) We met at a conference

d) One contacted the other exactly for the purpose of collaboration

3.3 How would you describe your relationship with your co-author

a) We were friends when we started working on the paper

b) We became friends while we were working on the paper

c) Our relationship is purely professional

3.4 Have you and your co-author ever applied for the same jobs?

a) yes

b) no

c) I do not know

Table 9 shows additional descriptive statistics beyond the ones already displayed in Sect. 6. It compares the data for respondents with those for the overall sample. 317 of the surveyed scholars responded, which corresponds to a response rate of $54.75 \%$. No significant differences between the two groups can be observed. The sample of survey respondents is representative of the overall sample, non-response bias does not appear to matter.

Table 10 shows descriptive statistics for the 83 articles, for which responses by both authors were available. Although there is substantial variation, on average the shares of the three tasks that the two authors claimed for themselves, respectively, add up to about 100 percent. This provides further support for the assumption that the respondents answered the survey questions honestly. 
Table 9 Survey data: additional descriptive statistics

\begin{tabular}{|c|c|c|c|c|c|c|c|c|}
\hline & \multicolumn{4}{|c|}{ All surveyed } & \multicolumn{4}{|c|}{ Respondents } \\
\hline & Mean & $\mathrm{SD}$ & Min. & Max. & Mean & $\mathrm{SD}$ & Min. & Max. \\
\hline Own age & 41.17 & 7.7992 & 27 & 70 & 41.27 & 7.9715 & 27 & 70 \\
\hline Age co-aut & 40.91 & 7.6854 & 27 & 70 & 40.93 & 7.3242 & 28 & 70 \\
\hline Age diff & 0.2683 & 11.09 & -34.94 & 34.94 & 0.3486 & 10.79 & -34.94 & 34.94 \\
\hline Female & 0.1209 & 0.3263 & 0 & 1 & 0.1009 & 0.3017 & 0 & 1 \\
\hline Co-aut fem & 0.1123 & 0.3160 & 0 & 1 & 0.1073 & 0.3099 & 0 & 1 \\
\hline Econ & 0.7703 & 0.4210 & 0 & 1 & 0.7791 & 0.4155 & 0 & 1 \\
\hline Co-aut econ & 0.7772 & 0.4165 & 0 & 1 & 0.7855 & 0.4111 & 0 & 1 \\
\hline CLm & 9.4890 & 8.5082 & 2.49 & 49.21 & 9.0838 & 8.4052 & 2.61 & 49.21 \\
\hline Own he & 138.06 & 241.87 & 1.10 & 3554 & 139.58 & 267.18 & 2.33 & 3554 \\
\hline Co-aut he & 135.06 & 240.04 & 1.10 & 3554 & 141.96 & 271.98 & 1.82 & 3554 \\
\hline GER & 0.7495 & 0.4337 & 0 & 1 & 0.7192 & 0.4501 & 0 & 1 \\
\hline AUT & 0.1244 & 0.3303 & 0 & 1 & 0.1451 & 0.3528 & 0 & 1 \\
\hline $\mathrm{CH}$ & 0.1261 & 0.3322 & 0 & 1 & 0.1356 & 0.3430 & 0 & 1 \\
\hline Year & 2004.47 & 5.5824 & 1981 & 2010 & 2003.86 & 6.0784 & 1981 & 2010 \\
\hline \# Obs. & \multicolumn{4}{|l|}{579} & \multicolumn{4}{|c|}{317 (rate: $54.75 \%$ ) } \\
\hline
\end{tabular}

Age is age in the year of publication. CLm and hc computed as in baseline case without human capital depreciation. Other than in the main part of the paper, age difference is not given in absolute values, i.e., it can become negative

Table 10 Survey data: papers of which both authors responded

Percentages; Sample size is 92

\begin{tabular}{lrlll}
\hline & \multicolumn{1}{c}{ Mean } & SD & Min. & Max. \\
\hline Sum concept & 101.1957 & 19.2064 & 30 & 140 \\
Sum tech & 98.1522 & 19.4388 & 40 & 160 \\
Sum writing & 102.5000 & 18.3749 & 60 & 150 \\
\hline
\end{tabular}

\section{Appendix 2: Survey evidence: Supplementary outputs}

Table 11 shows the complete regression output for specification (4) in Table 3. As also discussed in Sect. 4.2, there is a small positive correlation between quality of the journal and article appears in and both authors being women, and a strong negative correlation between journal quality and both authors identifying as business researchers.

Table 12 repeats regressions from Tables 7 and 8, but also reports the coefficients for the additional controls. Only very few of these coefficients are significant. Only one distance measure $(<100 \mathrm{~km})$ is correlated with a scholar's share of the idea that lead to the article. The better a scholar's prior publication record, the less of the technical tasks he performed. The better the co-author's publication record, the smaller a scholar's share in writing down the results. If, on the other hand, the co-author is female, scholars tend to write more. Scholars affiliated with Swiss universities are more likely to have been friends when they started collaborating. If the authors knew each other for longer than 3 years, it is also more likely that they were friends before they started to work together. Mentor-protégé relationships tend to reduce the probability of having been friends before. That two co-authors have ever, i.e., before or after their collaboration, applied for the same jobs, is less likely the higher-ranked the journal in which the 
Table 11 Non-structural estimates
Dependent variable:

CLm*1,000; OLS regression;

$\delta=0$; robust standard errors in parentheses; *** $p<0.01$, $* * p<0.05, * p<0.1$

\begin{tabular}{ll}
\hline & Full model \\
\hline Constant & $1,711.638$ \\
& $(9,750.774)$ \\
$H_{1}$ & $3.775^{* * *}$ \\
$H_{2}$ & $(0.857)$ \\
& $12.674 * * *$ \\
$H_{1} \cdot H_{2}$ & $(2.804)$ \\
& 0.003 \\
Average age & $(0.006)$ \\
& $747.872^{*}$ \\
Average squared & $(445.018)$ \\
& $-13.494 * * *$ \\
$I(d<7)$ & $(5.022)$ \\
$I(d>13)$ & 52.664 \\
& $(654.236)$ \\
$I(d<7) \cdot H_{1} \cdot H_{2}$ & -795.934 \\
$I(d>13) \cdot H_{1} \cdot H_{2}$ & $(706.681)$ \\
& -0.003 \\
Both female & $(0.007)$ \\
& $-0.016 * * *$ \\
Male/female & $(0.006)$ \\
& $3,708.324$ \\
Business administration & $(2,276.198)$ \\
Ba/econ & $-1,082.51^{*}$ \\
& $(615.624)$ \\
\# Collab's before & $-1,805.453^{* * *} *$ \\
Year dummies & $(647.838)$ \\
$\mathrm{R}^{2}$ & 228.560 \\
Observations & $(923.875)$ \\
& 8.375 \\
& $(128.950)$ \\
& Yes \\
& 0.1394 \\
& 1,470 \\
\hline &
\end{tabular}

article they have written has appeared in. Competition on the job market is also less common among scholars affiliated with Austrian institutions.

Table 13 shows robustness checks for the regressions from Table 7 in the main body of the paper. Two restrictions apply to the sample now: (i) I only use papers of which both authors responded; (ii) the sum of the contributions that I use as dependent variable must not lie outside [80, 120], which roughly corresponds to a range one standard deviation around the mean (see Table 10). For this restricted sample, it may seem more likely that the authors responded correctly. The statistical significance of some coefficients in Table 7 may, thus, be due to misreporting of individual contributions, which may be correlated with the respondents' age and the age difference with their co-author. On the other hand, this restricted sample also includes a high number of the modal respondents, who reported 50 percent. Some of them may have check "50 percent" simply because they did not remember the correct individual contributions, which may downward-bias the estimates in Table 13. Also note that the sample size decreased by more than half. With all the unreported control variables, not many degrees of freedom were left, anymore. 
Table 12 Coefficients on control variables

\begin{tabular}{|c|c|c|c|c|c|}
\hline \multirow[t]{2}{*}{ Dependent variable } & (1) & (2) & (3) & (4) & (5) \\
\hline & Share concept & Share tech & Share writ & Were friends & Competed \\
\hline Constant & $\begin{array}{l}31.990 * * * \\
(14.819)\end{array}$ & $\begin{array}{l}51.123 * * * \\
(13.965)\end{array}$ & $\begin{array}{l}62.346^{* * * *} \\
(12.843)\end{array}$ & $\begin{array}{l}54.703 * \\
(30.439)\end{array}$ & $\begin{array}{l}-11.683 \\
(30.065)\end{array}$ \\
\hline Own age & $\begin{array}{l}0.292 \\
(0.312)\end{array}$ & $\begin{array}{l}0.291 \\
(0.291)\end{array}$ & $\begin{array}{l}0.193 \\
(0.261)\end{array}$ & $\begin{array}{l}-0.058 * * * \\
(0.017)\end{array}$ & $\begin{array}{l}-0.048^{* *} \\
(0.021)\end{array}$ \\
\hline Age difference & $\begin{array}{l}0.044 \\
(0.253)\end{array}$ & $\begin{array}{l}-0.744 * * * \\
(0.226)\end{array}$ & $\begin{array}{l}-0.467 * * \\
(0.223)\end{array}$ & $\begin{array}{l}0.048 * * * \\
(0.013)\end{array}$ & $\begin{array}{l}0.030^{* * *} \\
(0.014)\end{array}$ \\
\hline Female & $\begin{array}{l}-2.643 \\
(5.133)\end{array}$ & $\begin{array}{l}-0.932 \\
(4.321)\end{array}$ & $\begin{array}{l}-2.651 \\
(3.784)\end{array}$ & $\begin{array}{l}-0.156 \\
(0.244)\end{array}$ & $\begin{array}{l}-0.379 \\
(0.354)\end{array}$ \\
\hline Co-aut fem & $\begin{array}{l}2.961 \\
(3.992)\end{array}$ & $\begin{array}{l}3.738 \\
(3.636)\end{array}$ & $\begin{array}{l}10.350 * * * \\
(3.368)\end{array}$ & $\begin{array}{l}0.202 \\
(0.328)\end{array}$ & $\begin{array}{l}-0.098 \\
(0.322)\end{array}$ \\
\hline Econ & $\begin{array}{l}-3.083 \\
(3.499)\end{array}$ & $\begin{array}{l}-1.738 \\
(4.238)\end{array}$ & $\begin{array}{l}-0.586 \\
(4.477)\end{array}$ & $\begin{array}{l}-0.216 \\
(0.358)\end{array}$ & $\begin{array}{l}0.232 \\
(0.302)\end{array}$ \\
\hline Co-aut econ & $\begin{array}{l}1.629 \\
(3.313)\end{array}$ & $\begin{array}{l}-4.894 \\
(3.946)\end{array}$ & $\begin{array}{l}-3.841 \\
(4.278)\end{array}$ & $\begin{array}{l}-0.165 \\
(0.363)\end{array}$ & $\begin{array}{l}-0.460 \\
(0.303)\end{array}$ \\
\hline CLm & $\begin{array}{l}0.172 \\
(0.186)\end{array}$ & $\begin{array}{l}0.094 \\
(0.163)\end{array}$ & $\begin{array}{l}-0.265^{*} \\
(0.135)\end{array}$ & $\begin{array}{l}0.010 \\
(0.013)\end{array}$ & $\begin{array}{l}-0.051^{* * * *} \\
(0.017)\end{array}$ \\
\hline Own he & $\begin{array}{l}-0.005 \\
(0.005)\end{array}$ & $\begin{array}{l}-0.012 * * \\
(0.005)\end{array}$ & $\begin{array}{l}0.002 \\
(0.005)\end{array}$ & $\begin{array}{l}-0.000 \\
(0.000)\end{array}$ & $\begin{array}{l}-0.000 \\
(0.000)\end{array}$ \\
\hline Co-aut he & $\begin{array}{l}-0.013 \\
(0.009)\end{array}$ & $\begin{array}{l}0.010 \\
(0.008)\end{array}$ & $\begin{array}{l}-0.011 * * \\
(0.005)\end{array}$ & $\begin{array}{l}0.001 * * \\
(0.000)\end{array}$ & $\begin{array}{l}0.000 \\
(0.000)\end{array}$ \\
\hline AUT & $\begin{array}{l}0.819 \\
(4.395)\end{array}$ & $\begin{array}{l}4.071 \\
(3.822)\end{array}$ & $\begin{array}{l}5.750 * \\
(3.460)\end{array}$ & $\begin{array}{l}0.374 \\
(0.274)\end{array}$ & $\begin{array}{l}-0.888^{* * * *} \\
(0.337)\end{array}$ \\
\hline $\mathrm{CH}$ & $\begin{array}{l}4.934 \\
(3.339)\end{array}$ & $\begin{array}{l}-4.865 \\
(4.297)\end{array}$ & $\begin{array}{l}5.320 \\
(3.644)\end{array}$ & $\begin{array}{l}0.619 * * \\
(0.249)\end{array}$ & $\begin{array}{l}-0.077 \\
(0.314)\end{array}$ \\
\hline Distance (>100 km) & $\begin{array}{l}-1.345 \\
(3.208)\end{array}$ & $\begin{array}{l}-1.188 \\
(3.285)\end{array}$ & $\begin{array}{l}-2.716 \\
(2.988)\end{array}$ & $\begin{array}{l}0.163 \\
(0.219)\end{array}$ & $\begin{array}{l}-0.097 \\
(0.240)\end{array}$ \\
\hline Distance $(<100 \mathrm{~km})$ & $\begin{array}{l}-11.662 * \\
(6.755)\end{array}$ & $\begin{array}{l}-8.406 \\
(6.308)\end{array}$ & $\begin{array}{l}-8.296 \\
(5.181)\end{array}$ & $\begin{array}{l}-0.497 \\
(0.352)\end{array}$ & $\begin{array}{l}0.058 \\
(0.517)\end{array}$ \\
\hline Met $>3$ years before & $\begin{array}{l}3.556 \\
(10.220)\end{array}$ & $\begin{array}{l}0.970 \\
(8.998)\end{array}$ & $\begin{array}{l}-17.632 * \\
(9.019)\end{array}$ & $\begin{array}{l}1.676^{* * * *} \\
(0.632)\end{array}$ & $\begin{array}{l}-0.014 \\
(0.747)\end{array}$ \\
\hline Met $<3$ years before & $\begin{array}{l}-0.391 \\
(10.590)\end{array}$ & $\begin{array}{l}-0.129 \\
(9.158)\end{array}$ & $\begin{array}{l}-17.690 * * \\
(8.869)\end{array}$ & $\begin{array}{l}0.613 \\
(0.640)\end{array}$ & $\begin{array}{l}-0.123 \\
(0.761)\end{array}$ \\
\hline Mentor-protégé & $\begin{array}{l}-2.665 \\
(3.299)\end{array}$ & $\begin{array}{l}2.349 \\
(3.243)\end{array}$ & $\begin{array}{l}4.613 * \\
(2.659)\end{array}$ & $\begin{array}{l}-0.679 * * * \\
(0.204)\end{array}$ & $\begin{array}{l}-0.319 \\
(0.230)\end{array}$ \\
\hline Conference & $\begin{array}{l}1.052 \\
(5.608)\end{array}$ & $\begin{array}{l}-3.369 \\
(5.531)\end{array}$ & $\begin{array}{l}5.726 \\
(3.970)\end{array}$ & $\begin{array}{l}-0.259 \\
(0.311)\end{array}$ & $\begin{array}{l}-0.187 \\
(0.364)\end{array}$ \\
\hline Contacted & $\begin{array}{l}1.460 \\
(5.420)\end{array}$ & $\begin{array}{l}-3.315 \\
(4.748)\end{array}$ & $\begin{array}{l}-6.251 \\
(4.444)\end{array}$ & $\begin{array}{l}-0.530 * \\
(0.310)\end{array}$ & $\begin{array}{l}0.079 \\
(0.353)\end{array}$ \\
\hline Year & Dummies & Dummies & Dummies & Linear & Linear \\
\hline Method & OLS & OLS & OLS & Probit & Probit \\
\hline (Pseudo-) $\mathrm{R}^{2}$ & 0.1224 & 0.2484 & 0.1959 & 0.2204 & 0.1179 \\
\hline Observations & 289 & 289 & 289 & 289 & 294 \\
\hline
\end{tabular}

OLS and Probit regression; robust standard errors; columns (1)-(3): standard errors in parentheses; columns (4)-(5): z statistics in parentheses additional controls include indicators for respondent and co-author being female or economists, respectively, their human capital endowments, the article score CLm, indicators for distance during collaboration, how long the authors knew each other and how their collaboration started, as well as year and country dummies

$* * * p<0.01, * * p<0.05, * p<0.1$ 
Table 13 Concept, technique, writing, and age for subsample with sum $\in[80,120]$

\begin{tabular}{|c|c|c|c|c|c|c|}
\hline \multirow{2}{*}{$\begin{array}{l}\text { Dependent } \\
\text { variable }\end{array}$} & (1) & (2) & (3) & (4) & (5) & (6) \\
\hline & Share concept & Rel. concept & Share tech & Rel. tech & Share writing & Rel. writing \\
\hline \multicolumn{7}{|l|}{ All respondents } \\
\hline Own age & $\begin{array}{l}0.227 \\
(0.654)\end{array}$ & $\begin{array}{l}-0.005 \\
(0.009)\end{array}$ & $\begin{array}{l}0.240 \\
(0.756)\end{array}$ & $\begin{array}{l}0.009 \\
(0.013)\end{array}$ & $\begin{array}{l}-0.072 \\
(0.565)\end{array}$ & $\begin{array}{l}-0.001 \\
(0.009)\end{array}$ \\
\hline Age difference & $\begin{array}{l}0.236 \\
(0.378)\end{array}$ & $\begin{array}{l}0.009 \\
(0.006)\end{array}$ & $\begin{array}{l}-0.609 \\
(0.445)\end{array}$ & $\begin{array}{l}-0.013 \\
(0.008)\end{array}$ & $\begin{array}{l}-0.217 \\
(0.387)\end{array}$ & $\begin{array}{l}-0.001 \\
(0.006)\end{array}$ \\
\hline Controls & Yes & Yes & Yes & Yes & Yes & Yes \\
\hline $\mathrm{R}^{2}$ & 0.1486 & 0.2018 & 0.2486 & 0.2776 & 0.1431 & 0.2413 \\
\hline \multicolumn{7}{|l|}{ Older authors } \\
\hline Own age & $\begin{array}{l}-0.973 \\
(0.836)\end{array}$ & $\begin{array}{l}-0.016 \\
(0.012)\end{array}$ & $\begin{array}{l}0.139 \\
(0.834)\end{array}$ & $\begin{array}{l}0.015 \\
(0.019)\end{array}$ & $\begin{array}{l}0.184 \\
(0.941)\end{array}$ & $\begin{array}{l}0.014 \\
(0.014)\end{array}$ \\
\hline Age difference & $\begin{array}{l}1.503 \\
(0.907)\end{array}$ & $\begin{array}{l}0.018 \\
(0.013)\end{array}$ & $\begin{array}{l}-0.099 \\
(1.080)\end{array}$ & $\begin{array}{l}-0.021 * \\
(0.025)\end{array}$ & $\begin{array}{l}-0.301 \\
(1.233)\end{array}$ & $\begin{array}{l}-0.000 \\
(0.019)\end{array}$ \\
\hline Controls & Yes & Yes & Yes & Yes & Yes & Yes \\
\hline $\mathrm{R}^{2}$ & 0.5753 & 0.6274 & 0.7097 & 0.6460 & 0.4788 & 0.6320 \\
\hline $\begin{array}{l}\text { Observations } \\
\text { Younger authors }\end{array}$ & 72 & 72 & 68 & 68 & 67 & 67 \\
\hline Own age & $\begin{array}{l}0.721 \\
(0.814)\end{array}$ & $\begin{array}{l}-0.001 \\
(0.011)\end{array}$ & $\begin{array}{l}1.039 \\
(1.047)\end{array}$ & $\begin{array}{l}0.028 \\
(0.017)\end{array}$ & $\begin{array}{l}0.055 \\
(0.984)\end{array}$ & $\begin{array}{l}-0.018 \\
(0.015)\end{array}$ \\
\hline Age difference & $\begin{array}{l}0.337 \\
(0.490)\end{array}$ & $\begin{array}{l}0.012 \\
(0.007)\end{array}$ & $\begin{array}{l}0.622 \\
(0.850)\end{array}$ & $\begin{array}{l}0.006 \\
(0.015)\end{array}$ & $\begin{array}{l}-0.108 \\
(0.523)\end{array}$ & $\begin{array}{l}0.000 \\
(0.009)\end{array}$ \\
\hline Controls & Yes & Yes & Yes & Yes & Yes & Yes \\
\hline $\mathrm{R}^{2}$ & 0.5912 & 0.7052 & 0.5655 & 0.5948 & 0.4507 & 0.6481 \\
\hline Observations & 71 & 71 & 70 & 70 & 72 & 72 \\
\hline
\end{tabular}

OLS regression; robust standard errors; standard errors in parentheses; additional controls include indicators for respondent and co-author being female or economists, respectively, their human capital endowments, the article score CLm, indicators for distance during collaboration, how long the authors knew each other and how their collaboration started, as well as year and country dummies

$* * * p<0.01, * * p<0.05, * p<0.1$

\section{References}

Alchian AA, Demsetz H (1972) Production, information costs, and economic organization. Am Econ Rev 62(5):777-95, http://ideas.repec.org/a/aea/aecrev/v62y1972i5p777-95.html

Arrow KJ, Chenery H, Minhas B, Solow RM (1961) Capital-labor substitution and economic efficiency. Rev Econ Stat 43(3):225-250

Azoulay P, Graff Zivin JS, Wang J (2010) Superstar extinction. Q J Econ 125(2):549-589, http://ideas. repec.org/a/tpr/qjecon/v125y2010i2p549-589.html

Barnett AH, Ault RW, Kaserman DL (1988) The rising incidence of co-authorship in economics: further evidence. Rev Econ Stat 70(3):539-43, http://ideas.repec.org/a/tpr/restat/v70y1988i3p539-43.html

Boschini A, Sjgren A (2007) Is team formation gender neutral? Evidence from coauthorship patterns. J Labor Econ 25(2):325-365

Cacioppo JT, Berntson GG (2005) Social neuroscience: key readings. Psychology Press, New York

Cacioppo JT, Visser PS, Pickett CL (2006) Social neuroscience: people thinking about thinking people. The MIT Press, Cambridge

Cattell RB (1963) Theory of fluid and crystallized intelligence: a critical experiment. J Educ Psychol 54(1):1-22

Combes PP, Linnemer L (2010) Inferring missing citations: a quantitative multi-criteria ranking of all journals in economics. In: Working papers halshs-00520325, HAL, http://ideas.repec.org/p/hal/wpaper/ halshs-00520325.html

De Solla Price DJ, Beaver DD (1966) Collaboration in an invisible college. Am Psychol 21(11):1011-1018 
Ductor L (2014) Does co-authorship lead to higher academic productivity? Oxford Bull Econ Stat (forthcoming)

Fafchamps M, Goyal S, van der Leij MJ (2010) Matching and network effects. J Eur Econ Assoc 8(1):203231

Galenson DW (2006) Old masters and young geniuses: the two life cycles of artistic creativity. Princeton University Press, Princeton

Galenson DW, Weinberg BA (2000) Age and the quality of work: the case of modern american painters. J Polit Econ 108(4):761-777, http://ideas.repec.org/a/ucp/jpolec/v108y2000i4p761-777.html

Galenson DW, Weinberg BA (2001) Creating modern art: the changing careers of painters in france from impressionism to cubism. Am Econ Rev 91(4):1063-1071, http://ideas.repec.org/a/aea/aecrev/ v91y2001i4p1063-1071.html

Griliches Z (1969) Capital-skill complementarity. Rev Econ Stat 51(4):465-68, http://ideas.repec.org/a/ tpr/restat/v51y1969i4p465-68.html

Hamermesh DS, Oster SM (2002) Tools or toys? The impact of high technology on scholarly productivity. Econ Inq 40(4):539-555, http://ideas.repec.org/a/oup/ecinqu/v40y2002i4p539-555.html

Horn JL, Cattell RB (1966) Refinement and test of the theory of fluid and crystallized general intelligences. J Educ Psychol 57(5):253-270

Jones BF (2009) The burden of knowledge and the "death of the renaissance man": Is innovation getting harder? Rev Econ Stud 76(1):283-317, http://ideas.repec.org/a/bla/restud/v76y2009i1p283-317.html

Jones BF (2010a) Age and great invention. Rev Econ Stat 92(1):1-14, http://ideas.repec.org/a/tpr/restat/ v92y2010i1p1-14.html

Jones BF (2010b) As science evolves, how can science policy? In: Lerner J, Stern S (eds) Innovation policy and the economy, vol 11, NBER, pp 103-131

Laband DN (1987) A qualitative test of journal discrimination against women. East Econ J 13(2):149-153, http://ideas.repec.org/a/eej/eeconj/v13y1987i2p149-153.html

Laband DN, Piette MJ (1995) Team production in economics: division of labor or mentoring? Labour Econ 2(1):33-40, http://ideas.repec.org/a/eee/labeco/v2y1995i1p33-40.html

Laband DN, Tollison RD (2000) Intellectual collaboration. J Polit Econ 108(3):632-661, http://ideas.repec. org/a/ucp/jpolec/v108y2000i3p632-661.html

McDowell JM (1982) Obsolescence of knowledge and career publication profiles: some evidence of differences among fields in costs of interrupted careers. Am Econ Rev 72(4):752-68, http://ideas.repec. org/a/aea/aecrev/v72y1982i4p752-68.html

McDowell JM, Singell LD, Stater M (2006) Two to tango? Gender differences in the decisions to publish and coauthor. Econ Inq 44(1):153-168, http://ideas.repec.org/a/oup/ecinqu/v44y2006ilp153-168.html

Murphy KM, Topel RH (1985) Estimation and Inference in two-step econometric models. J Bus Econ Stat 3(4):370-79, http://ideas.repec.org/a/bes/jnlbes/v3y1985i4p370-79.html

Oster SM, Hamermesh DS (1998) Aging and productivity among economists. Rev Econ Stat 80(1):154-156, http://ideas.repec.org/a/tpr/restat/v80y1998i1p154-156.html

Oswald AJ (2007) An examination of the reliability of prestigious scholarly journals: evidence and implications for decision-makers. Economica 74(293):21-31, http://ideas.repec.org/a/bla/econom/ v74y2007i293p21-31.html

Palacios-Huerta I, Volij O (2004) The measurement of intellectual influence. Econometrica 72(3):963-977, http://ideas.repec.org/a/ecm/emetrp/v72y2004i3p963-977.html

Prat A (2002) Should a team be homogeneous? Eur Econ Rev 46(7):1187-1207, http://ideas.repec.org/a/ eee/eecrev/v46y2002i7p1187-1207.html

Rauber M, Ursprung HW (2008) Life cycle and cohort productivity in economic research: the case of germany. Ger Econ Rev 9:431-456, http://ideas.repec.org/a/bla/germec/v9y2008ip431-456.html

Ursprung HW, Zimmer M (2007) Who is the platz-hirsch of the german economics profession? a citation analysis. J Econ Stat (Jahrbuecher fuer Nationaloekonomie und Statistik) 227(2):187-208, http://ideas. repec.org/a/jns/jbstat/v227y2007i2p187-208.html

Wuchty S, Jones BF, Uzzi B (2007) The increasing dominance of teams in production of knowledge. Science 316(5827):1036-1039 